\title{
Optimization of Process Parameters of EDM of Inconel 617 by Taguchi Based PCA and GRA Technique and Effect of Recast Layer Formation
}

\author{
Shrikant Vastrakar, Sharda Pratap Shrivas, Amit Kumar Vishwakarma, Sanjay Kumar \\ Vaidya, Ashish Kumar Khandelwal
}

\begin{abstract}
Inconel materials are manufactured in various series which have differences in their chemical composition and hence in its physical and chemical properties. These alloy materials are known for their high strength, corrosion resistance and oxidation resistance. They are not easily machine-able through conventional machining, due to rapid work hardening tendency, high toughness and hardness, tendency to form built up edges, hence for their machining, non conventional machining equipments like EDM are used. A number of experiments has been performed to optimize process parameters of EDM on different series of Inconel material like Inconel 625, Inconel 718, Inconel 601, Inconel hastelloy C-276, Inconel 690 etc. by different optimization technique Taguchi, PCA, GRA etc however there is a lack of data available for optimization of process parameters of EDM machining for Inconel 617. So in this paper optimization of process parameters like Pulse on time, peak current, gap voltage have been done by taking Material Removal Rate and Tool Wear Rate as response variables. Other process parameters have been kept constant during EDM process. It is found that for different values of process parameters pattern of variation of MRR and TWR is different. Also the effect of recast layer formation on MRR and TWR has been analyzed and it is found that at high Peak Current and high Pulse on Time, tendency of formation of recast layer is high. Formation of recast layer adversely affects MRR and TWR i.e. it reduces MRR and TWR. Also Results obtained from PCA and GRA has been compared and it is found that both methods give same optimum set of process parameters but they have differences in pattern of variation of MRR and TWR.
\end{abstract}

Keywords : Electric Discharge Machining, Inconel 617, Material Removal Rate, Tool Wear rate, Pulse on time, Peak

Revised Manuscript Received on December 30, 2019.

* Correspondence Author

Amit Kumar VishwakarmA, Assistant Professor, Mechanical Engineering Department, Chouksey Engineering College Bilaspur under Chhattisgarh Swami Vivekananda University Bhilai.

Sanjay Kumar Vaidya, Assistant Professor, Mechanical Engineering Department, Chouksey Engineering College Bilaspur under Chhattisgarh Swami Vivekananda University Bhilai.

Ashish Kumar Khandelwal, Head Department of Mechanical Engineering, Chouksey Engineering College Bilaspur under Chhattisgarh Swami Vivekananda University Bhilai.

(C) The Authors. Published by Blue Eyes Intelligence Engineering and Sciences Publication (BEIESP). This is an open access article under the CC BY-NC-ND license (http://creativecommons.org/licenses/by-nc-nd/4.0/) current, Gap Voltage, GRA(Gray Relation Analysis), Taguchi design, PCA(Principle Component Analysis), Recast Layer Formation.

\section{I.INTRODUCTION}

Inconel 617 is used in many important engineering equipments and machines like in combustion cans, super critical boilers, in aircraft as transition liners and in gas turbines because of its high strength and corrosion resistance property over a wide range of temperature. This material is also used as high temperature resisting elements because of its corrosion resistance property at very high temperature. [11] It is also very useful alloy for nuclear power plants and fossil fuel based power plants as temperature and corrosion resisting substance. So availability of optimum values of process parameter of machining of Inconel 617 can increase the efficiency of related industries.[5] [34] [26] Electric Discharge Machining process uses a combined process of electric and thermo effect to machine work piece. Extra desired work material is removed by melting that portion by generating the spark between work piece and tool both of which are conducting material. This spark is generated by applying voltage and hence peak current between electrodes. Machined scrap is removed by the dielectric fluid by applying flushing pressure. After achieving required depth of cut machining is stopped and impression on the work piece material is formed as the same shape of electrode.[7] [21]. (Patel \& Maity, 2014) explained basics of EDM process and its advantage. (Harshalkumar, Mundane, Kale, \& Giri, 2018) explained different process parameters which greatly affects EDM process[7]. (Mishra, Datta, Masanta, \& Mahapatra, 2018) proved suitability of copper electrode for EDM of Inconel material[17]. (Upadhyay, Rahul, Datta, Mahapatra, \& Biswal, 2018) used L27 orthogonal array and explained taguchi methodology of design of experiment, they also explained effect of recast layer formation. [1] [33] [34]. (Mohanta \& Maity, 2013) used different types of techniques of optimization for comparing their results[18]. 


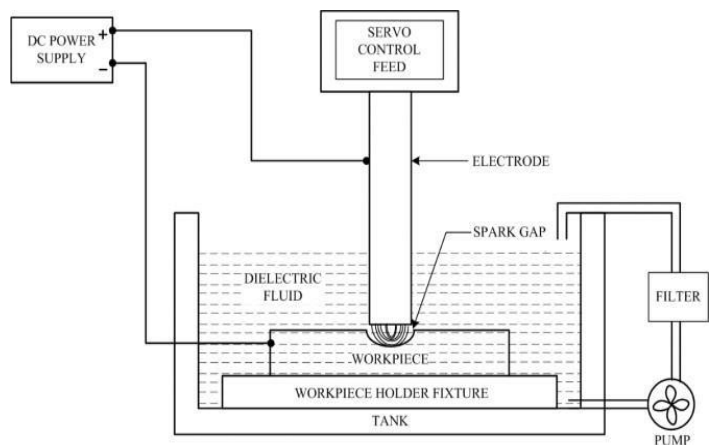

Fig.1. EDM Process [7]

\section{A. Types of EDM}

- Die Sinking EDM

In this type of EDM, Tool electrode is in the form of Die, which means the impression on the work piece material is formed as per the shape of electrode die. Work piece is fitted in work bench where as tool is fitted on the tool holder, both electrode must be electrical conductor .After that these set up is immersed in insulating dielectric fluid in often case Kerosin/Transformer oil/EDM oil.[25]

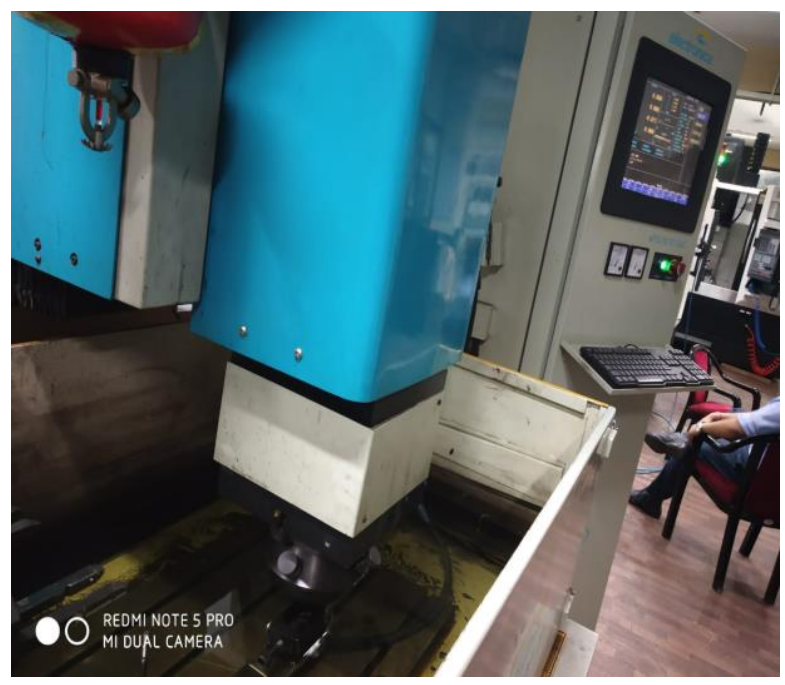

Fig.2. EDM machine

\section{- WIRE EDM}

In wire EDM also called electric discharge wire cutting process, work material is removed by generating spark between moving wire and work piece in the presence of dielectric fluid. Any hard material can be cut by this process but both must be electrical conductor[15].

\section{II.MATERIALS AND METHODS}

EDM has been performed in Inconel 617 by using copper electrode. Inconel 617 is used in many important engineering equipments and machines like in combustion cans, super critical boilers, in aircraft as transition liners and in gas turbines because of its high strength and corrosion resistance property over a wide range of temperature.

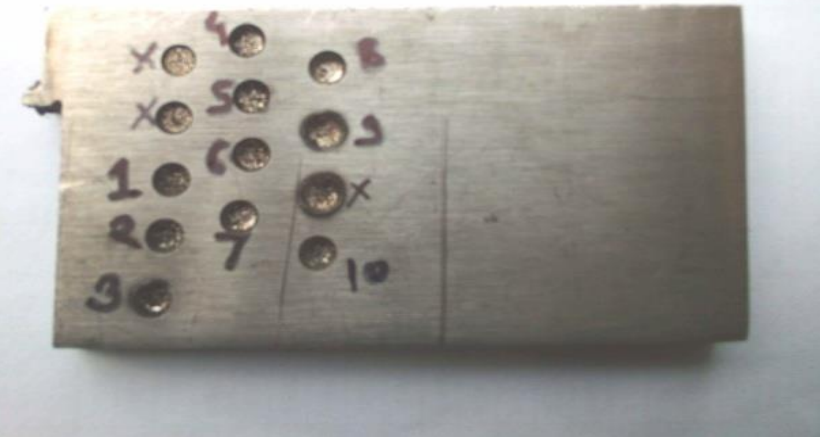

Fig.3. Inconel 617 Machined Work Material

This material is also used as high temperature resisting elements because of its corrosion resistance property at very high temperature.[5] [34]. Copper electrode has been chosen because of its better conductivity and low wear rate.

Table-1: Inconel 617 composition

\begin{tabular}{|l|l|}
\hline Chemical composition of Inconel 617 & \multicolumn{1}{|c|}{$\%$} \\
\hline Nickel & 44.5 \\
\hline Chromium & $20-24$ \\
\hline Iron & 3 max \\
\hline Aluminium & $0.8-1.5$ \\
\hline Carbon & $0.05-0.15$ \\
\hline Manganese & 1 max \\
\hline Sulphur & 0.015 \\
\hline Silicon & 1 max \\
\hline Copper & 0.5 max \\
\hline Cobalt & $10-15$ \\
\hline Molybdenum & $8-10$ \\
\hline Titanium & 0.6 max \\
\hline Boron & 0.006 \\
\hline
\end{tabular}

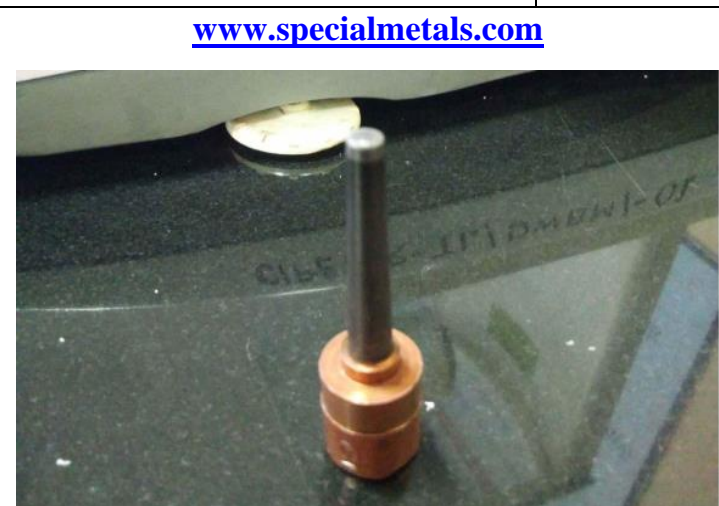

Fig. 4: Copper Tool

\section{A. Taguchi Method of Design Experiment}

Taguchi method of optimization is most recent development for optimization used in design, manufacturing and quality assurance methodology. This method emphasizes superior performance design of manufacturing process and product to deliver best results. In Taguchi method an integration of DOEs (design of experiments) with process parameters are done hence best result is obtained using minimum number of experimental data. In this paper L9 Orthogonal array have been used for DOEs of EDM of Inconel 617 by taking total 9 experiments.[9] [12]

\section{Blue Eyes Intelligence Engineering \& Sciences Publication}

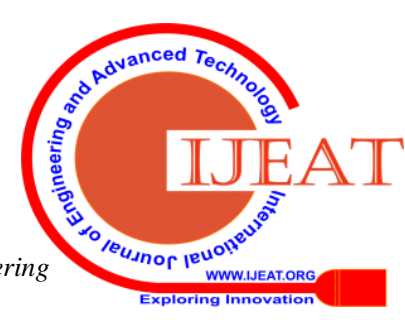


Table- 2: L9 Orthogonal array

\begin{tabular}{|l|l|l|l|}
\hline & $1^{\text {st }}$ Parameter & $2^{\text {nd }}$ Parameter & $\begin{array}{l}3^{\text {rd }} \\
\text { Parameter }\end{array}$ \\
\hline 1 & 1 & 1 & 1 \\
\hline 2 & 1 & 2 & 2 \\
\hline 3 & 1 & 3 & 3 \\
\hline 4 & 2 & 1 & 2 \\
\hline 5 & 2 & 2 & 3 \\
\hline 6 & 2 & 3 & 1 \\
\hline 7 & 3 & 1 & 3 \\
\hline 8 & 3 & 2 & 1 \\
\hline 9 & 3 & 3 & 2 \\
\hline
\end{tabular}

\section{B. Signal to Noise Ratio}

It tells deviation of performance characteristics from desired values i.e. ratio of mean to standard deviation[18].

-Higher the better (HB) for MRR.

-Lower the better (LB) for TWR.

Taguchi's signal to noise ratio in which desired output i expressed as log function is treated as objective function fo optimization

$\mathrm{S} / \mathrm{N}_{\mathrm{HB}}=-10 \log \left[\frac{1}{T} \sum_{i=1}^{T} 1 / \mathrm{X}^{2}\right]$ For higher the better

$\mathrm{S} / \mathrm{N}_{\mathrm{LB}}=-10 \log \left[\frac{1}{T} \sum_{i=1}^{T} X^{2}\right] \quad$ For lower the better

In this eq ${ }^{\mathrm{n}} \mathrm{Y}_{\mathrm{i}}=$ response characteristic value for $\mathrm{i}^{\text {th }}$ experiment.

$\mathrm{T}=$ total number of trials

\section{Grey Relation Analysis}

This analysis gives the degree of proximity according to similarity or difference among the development situations of factors. The grey relational analysis is used to convert the multi responses which need to be optimized to a single objective [10] [18].

$1^{\text {st }}$ Step

In this step response parameters are converted into normalize data by applying formula

$x_{i}(k)=x_{i}-x_{\min } / x_{\max }-x_{\min } \quad$ For Higher the better
$x_{i}(k)=x_{\max }-x_{i} / x_{\max }-x_{\min } \quad$ For Lower the better

$\mathrm{i}=1,2,3 \ldots \ldots \mathrm{m} \quad$ where $\mathrm{m}$ is no. of experiment performed.

$2^{\text {nd }}$ Step - Calculation of deviation $\Delta$ (Grey

Relation Generation)

In next step of Gray Relation Generation deviation $\Delta$ is calculated by formula for each response parameter and for

$$
\Delta=1-\mathrm{X}_{\mathrm{i}}(\mathrm{k}) \text { is }
$$

Step3 - Calculation of Grey Relation Co-efficient

After that Gray Relation coefficient is calculated by formula

$\Upsilon_{i}=\frac{(\Delta \min +€ \Delta \max )}{\Delta \mathrm{i}+€ \Delta \max }$ where $€$ (distinguishing co-efficient) i generally put as 0.5

where $\Upsilon_{i}$ is the grey relation co-efficient of process response for $\mathrm{i}^{\text {th }}$ experiment.

Step 4- Calculation of Grey Relation Grade (OQPI)

GRG (Grey Relation Grade is Calculated by averaging the values of different response parameters i.e. MRR and each experiment

TWR. This GRG is the combined effect of all response parameter.

OQPI for $t^{\text {th }}$ response parameter is calculated by following formula

OQPI $_{\mathrm{t}}=\sum_{t=1}^{r} W_{\mathrm{t}} \Upsilon_{\mathrm{it}} \quad$ where $\mathrm{r}$ is total no. of response variable.

But practically $\mathrm{OQPI}_{t}$ is calculated by averaging of Grey Relation coefficient of all $r$ response parameters for a particular $i_{\text {th }}$ experiment. And this OQPI is calculated for all experiment.

\section{Weighted PCA (Taguchi Based)}

Taguchi method can only be applied in single response problem, multi response problem can't be solved by Taguchi method so to solve such multi response problem Weighted Principle component analysis method is used [3] [18].

First step - Computing Signal to Noise ratio for each process response of each experiment

Signal to Noise ratio can be calculated by following formula $\mathrm{S} / \mathrm{N}_{\mathrm{HB}}=\mathrm{jij}=-10 \log \left[\frac{1}{T} \sum_{i=1}^{T} 1 / \mathrm{X}^{2}\right]$ For higher the better (for MRR)

$\mathrm{S} / \mathrm{N}_{\mathrm{LB}}=\mathrm{yij}=-10 \log \left[\frac{1}{T} \sum_{i=1}^{T} X^{2}\right] \quad$ For lower the better ( for TWR)

Where $\mathrm{X}$ is values of response variables,

$\mathrm{T}$ is the number of experiment performed.

After conversion in signal to noise ratio each problem is converted in maximization problem.

Second step - Normalization of Computed Signal to Noise Ratio Computed signal to noise ratio is normalized by applying formula.

Normalized Value $Y_{\mathrm{ij}}(\mathrm{k})=\frac{\eta \mathrm{ij}-\mathrm{\eta j}(\min .)}{\mathrm{jj}(\max )-\eta \mathrm{j}(\min .)}$

$\mathrm{\eta}_{\mathrm{ij}}(\mathrm{k})$ is Signal to noise ratio of $\mathrm{k}^{\text {th }}$ performance index at $\mathrm{i}^{\text {th }}$ $(1,2,3 \ldots . .9)$ experiment of $j$ th process response $(j=1,2)$

Normalization of all values ( $\mathrm{S} / \mathrm{N}$ ratio of response variables) convert all the data between 0 to 1 .

Third Step - Apply formula of PCA analysis and obtain Principle Component and Eigen Values and Eigen Vectors

Find covariance matrix by this formula

$$
\begin{aligned}
& \operatorname{COV}(\mathrm{U}, \mathrm{V})=\sum_{i=1}^{n} \frac{(U-U a v g)(V-V a v g)}{n-1} \\
& \mathrm{C}=\left[\begin{array}{ll}
\operatorname{Cov}(U, U) & \operatorname{Cov}(U, V) \\
\operatorname{Cov}(V, U) & \operatorname{Cov}(V, V)
\end{array}\right]
\end{aligned}
$$

$$
[\mathrm{C}-\lambda \mathrm{I}]=\left[\begin{array}{ll}
\operatorname{Cov}(U, U) & \operatorname{Cov}(U, V) \\
\operatorname{Cov}(V, U) & \operatorname{Cov}(V, V)
\end{array}\right]-\left[\begin{array}{ll}
\lambda & 0 \\
0 & \lambda
\end{array}\right]=0
$$

Gives values of Eigen vector $\lambda_{1}$ and $\lambda_{2}$

And corresponding eigen vectors are calculated by applying formula

$\left[\mathrm{C}-\lambda_{1} \mathrm{I}\right]\left[\begin{array}{l}U 1 \\ V 1\end{array}\right]=0$ and $[\mathrm{C}-\lambda \mathrm{I}]\left[\begin{array}{l}U 2 \\ V 2\end{array}\right]=0$

obtain the q principal components corresponding to a trial (i) as follows

$\mathrm{Z}_{1}{ }^{\mathrm{i}}=\mathrm{a}_{11} \mathrm{Y}_{\mathrm{i} 1}+\mathrm{a}_{21} \mathrm{Y}_{\mathrm{i} 2}+\ldots \ldots \ldots \ldots \ldots \ldots \mathrm{a}_{\mathrm{pl}} \mathrm{Y}_{\text {ip }}(\mathrm{l}=1,2, \ldots \mathrm{q})$

Where $Y_{\text {ip }}$ is normalized signal to noise ratio of response parameter for $\mathrm{i}^{\text {th }}$ experiment and $\mathrm{p}^{\text {th }}$ response parameter. 


\section{Optimization of Process Parameters of EDM of Inconel 617 by Taguchi based PCA and GRA technique and effect of recast layer formation}

Where $\mathrm{a}_{11}, \mathrm{a}_{21} \ldots \ldots \ldots \ldots . . . \mathrm{a}_{\mathrm{pl}}$ are corresponding eigen vectors. parameter i.e. on MRR and TWR has been analyzed in this Step4 - Computing Multiple Performance Index (MPIpaper[1] [33] [34].

corresponding to each experiment

After that MPI for $\mathrm{i}^{\text {th }}$ experiment is calculated by applying formula

$$
\mathrm{MPI}^{\mathrm{i}}=\sum_{l=1}^{q} W 1 \mathrm{Zl}^{\mathrm{i}}
$$

\section{IV.EXPERIMENTAL SETUP}

Where $\mathrm{W}$ is accountability proportion calculated by following been performed on Inconel 617 material up to $3 \mathrm{~mm}$ depth formula

$$
\begin{aligned}
& \mathrm{W} 1=\frac{\lambda 1}{\lambda 1+\lambda 2+\lambda 3 \ldots \ldots \ldots+\lambda \mathrm{q}} \\
& \mathrm{W} 2=\frac{\lambda 2}{\lambda 1+\lambda 2+\lambda 3 \ldots \ldots \ldots+\lambda \mathrm{q}} \\
& \mathrm{Wq}=\frac{\lambda \mathrm{q}}{\lambda 1+\lambda 2+\lambda 3 \ldots \ldots \ldots+\lambda \mathrm{q}}
\end{aligned}
$$

The experiment no. which has the highest value of MPI will be Optimum and hence process parameters of that experiment will be optimum.

\section{E. Analyzing ANOVA Results}

ANOVA is used to analyze any significant difference between the means of three or more unrelated independent groups. It determines whether all groups are taken from common population or not. ANOVA is a ratio between Mean Sum of Squares between Variance $\left(\mathrm{MSS}_{\mathrm{B}}\right)$ to the Mean Sum of Squares within variance $\left(\mathrm{MSS}_{\mathrm{W}}\right)$ [24] [22] [18]. ANOVA $=\left(\right.$ MSS $\left._{B}\right) /\left(\right.$ MSS $\left._{W}\right)$ ANOVA is performed on results obtained from optimization techniques. In this paper ANOVA has been performed on MPI and also on Grey Relation Grade using Minitab software.

\section{III.OBJECTIVE OF EXPERIMENT}

So in this paper optimization of process parameters like Pulse on time, peak current, gap voltage have been done for the Electro Discharge Machining of Inconel 617 by calculating optimum values of MRR (Material Removal Rate) and TWR (Tool Wear Rate) keeping other process parameters constant.

Availability of optimum values of process parameter of machining of Inconel 617 can increase the efficiency of related industries.

Also Comparative Study of the results obtained from Taguchi based PCA and GRA is to be done in this paper [18]. Also the effect of Recast layer formation on response $\mathrm{mm}$ diameter. 3 process parameters namely Peak current, Pulse on Time and Gap Voltage have been analyzed for optimizing MRR and TWR by keeping other parameters as constant.[17] Initial experimental values of process parameters have been selected by analyzing different literature reviews.

\section{$M R R$}

It is the mass of work piece material removed per unit time. It can be formulized by

$$
\mathrm{MRR}=\frac{M 1-\mathrm{M} 2}{T}\left(\frac{\mu g m}{\sec }\right)
$$

this be converted in $\mathrm{mm}^{3} / \mathrm{min}$ by dividing this value with density of work piece material.

M1: Mass of work piece before machining.

M2: Mass of work piece after machining.

T: Machining Time (Jabbaripour, Sadeghi, Faridvand, \& Shabgard, 2012) [8]

TWR

It is defined as mass of tool removed per unit time and formulized as

TWR $=\frac{m 1-m 2}{T}\left(\frac{\mu g m}{\sec }\right)$

This can be converted in $\mathrm{mm}^{3} / \mathrm{min}$ by dividing with the density of Copper tool $m 1$ : Mass of tool before machining. $m 2$ : Mass of tool after machining.

T : Machining Time (Jabbaripour, Sadeghi, Faridvand, \& Shabgard, 2012) [8]

Table-3: Level of Variation

\begin{tabular}{|l|l|l|l|l|}
\hline Parameters & Notation & \multicolumn{4}{|l|}{ Level of Variation } \\
\hline & & 1 & 2 & 3 \\
\hline $\begin{array}{l}\text { Peak } \\
\text { Current } \mathrm{I}_{\mathrm{p}}\end{array}$ & A(Peak) & 10 & 15 & 20 \\
\hline $\begin{array}{l}\text { Pulse on } \\
\text { time } \mathrm{T}_{\text {on }}\end{array}$ & B(Pulse) & 50 & 100 & 150 \\
\hline $\begin{array}{l}\text { Gap Voltage } \\
\mathrm{V}_{\mathrm{g}}\end{array}$ & C(Gap) & 25 & 50 & 75 \\
\hline
\end{tabular}

Table-4: Other process parameters have kept Constant

\begin{tabular}{|l|l|}
\hline Parameters & Values \\
\hline Polarity & + Ve work piece \\
\hline Duty Factor & $80 \%$ \\
\hline Pulse off Time $(\mu \mathrm{sec})$ & 26 \\
\hline Max. deep $(\mathrm{mm})$ & 3 \\
\hline Electrode diameter $(\mathrm{mm})$ & 5 \\
\hline EDM feed rate $(\mu \mathrm{m} / \mathrm{sec})$ & 20 \\
\hline
\end{tabular}




\section{V.RESULT AND DISCUSSION}

Results obtained from EDM are given here in table form. Also the formulized data are arranged in table forms as below

Table- 5: L9 Readings from EDM

\begin{tabular}{|l|l|l|l|l|l|l|}
\hline S.no. & A & B & C & MRR $\left(\mathrm{mm}^{3} / \mathrm{min}\right)$ & $\begin{array}{c}\text { TWR } \\
\left(\mathrm{mm}^{3} / \mathrm{min}\right)\end{array}$ & Machining Time \\
\hline 1 & 1 & 1 & 1 & 4.687874 & 0.072753 & $11 \mathrm{~min} 44.25 \mathrm{sec}$ \\
\hline 2 & 1 & 2 & 2 & 4.628539 & 0.041455 & $11 \mathrm{~min} 06.76 \mathrm{sec}$ \\
\hline 3 & 1 & 3 & 3 & 3.686366 & 0.039144 & $14 \mathrm{~min} 55.58 \mathrm{sec}$ \\
\hline 4 & 2 & 1 & 2 & 5.475232 & 0.115718 & $9 \mathrm{~min} 36.76 \mathrm{sec}$ \\
\hline 5 & 2 & 2 & 3 & 4.873039 & 0.069656 & $11 \mathrm{~min} 17.49 \mathrm{sec}$ \\
\hline 6 & 2 & 3 & 1 & 4.260136 & 0.073074 & $12 \mathrm{~min} 54.96 \mathrm{sec}$ \\
\hline 7 & 3 & 1 & 3 & 5.096194 & 0.237355 & $11 \mathrm{~min} 15.99 \mathrm{sec}$ \\
\hline 8 & 3 & 2 & 1 & 3.641111 & 0.127687 & $14 \mathrm{~min} 47.06 \mathrm{sec}$ \\
\hline 9 & 3 & 3 & 2 & 1.568851 & 0.089955 & $36 \mathrm{~min} 35.86 \mathrm{sec}$ \\
\hline
\end{tabular}

A. Weighted PCA (Taguchi based)

Table- 6: Signal to Noise ratio and normalized signal to noise ratio

\begin{tabular}{|c|c|c|c|c|}
\hline & \multicolumn{2}{|c|}{ Signal to noise ratio $\left[\mathrm{y}_{\mathrm{ij}}(\mathrm{k})\right]$} & \multicolumn{2}{|c|}{$\begin{array}{l}\text { Normalized Value } Y_{\mathrm{ij}}(\mathrm{k}) \\
=\frac{\mathrm{nij}-\mathrm{nj}(\min )}{\mathrm{yj}(\max )-\mathrm{jj}(\min )}\end{array}$} \\
\hline & MRR & TWR & MRR(U) & TWR(V) \\
\hline 1. & 13.419519 & 22.762982 & 0.875785 & 0.656095 \\
\hline 2. & 13.308878 & 27.648462 & 0.865594 & 0.968173 \\
\hline 3. & 11.331969 & 28.146696 & 0.683498 & 1 \\
\hline 4. & 14.768051 & 18.731982 & 1 & 0.398600 \\
\hline 5. & 13.756094 & 23.140829 & 0.906787 & 0.680232 \\
\hline 6. & 12.588469 & 22.724742 & 0.799236 & 0.653652 \\
\hline 7. & 14.144919 & 12.492032 & 0.942602 & 0 \\
\hline 8. & 11.224678 & 17.877066 & 0.673615 & 0.343989 \\
\hline 9. & 3.911634 & 20.919494 & 0 & 0.538336 \\
\hline & & & $\mathrm{U}_{\mathrm{avg}}=0.638569$ & $\mathrm{~V}_{\text {avg }}=.582120$ \\
\hline
\end{tabular}

Table-7: Eigen Vector Table

\begin{tabular}{|c|l|l|}
\hline & \multicolumn{1}{|c|}{ MRR } & TWR \\
\hline Eigen Value & 0.109667 & 0.092170 \\
\hline Eigen Vector & $0.007741\left(\mathrm{U}_{1}\right)$ & $0.004700\left(\mathrm{U}_{1}\right)$ \\
\hline & $0.007741\left(\mathrm{U}_{2}\right)$ & $0.012787\left(\mathrm{U}_{2}\right)$ \\
\hline A.P. & 0.543344 & 0.456656 \\
\hline
\end{tabular}

Experimental Values clearly shows that set of Peak1, Pulse2, Gap2 has Maximum Value of MPI, Hence in L9 orthogonal array this set, is optimum. However the optimum level of Process Parameter can be further analysed by drawing main

\begin{tabular}{|l|l|c|r|l|}
\multicolumn{5}{|c|}{ Table- 8: MPI Table } \\
\hline & $Z_{1}{ }^{\mathrm{i}}$ & $\mathrm{Z}_{2}{ }^{\mathrm{i}}$ & MPI & Rank \\
\hline 1. & 0.009863 & 0.15169 & 0.012286 & 4 th \\
\hline 2. & 0.011251 & 0.019081 & 0.014287 & 1 st \\
\hline 3. & 0.009991 & 0.018078 & 0.013684 & 2nd \\
\hline 4. & 0.009614 & 0.012838 & 0.011086 & 6th \\
\hline 5. & 0.010217 & 0.015718 & 0.012729 & 3rd \\
\hline 6. & 0.009259 & 0.014545 & 0.011673 & 5th \\
\hline 7. & 0.007297 & 0.007297 & 0.007297 & 8th \\
\hline 8. & 0.006831 & 0.009613 & 0.008101 & 7th \\
\hline 9. & 0.002530 & 0.006884 & 0.004518 & 9th \\
\hline
\end{tabular}

effect plot using Taguchi Design in Minitab software. MPI Rank- Peak Current-1, Pulse on Time-2, Gap of Voltage-3. A mean effect plot for MPI (Larger the better) has been drawn. This graph shows the combined effect of process parameter on both MRR and TWR. It can be seen that MPI is decreasing as increase Peak Current. Which mean initial values of current is preferable for optimum result. It can also be seen that MPI is first increasing with increase in Pulse on time but after some point MPI decreases with increase in Pulse on Time. So optimum results can be found in $2^{\text {nd }}$ level of Pulse on Time i.e.100 micro seconds. As graph implies Gap Voltage has varying effect on MPI, firstly an incease with increase in gap voltage MPI is decreasing but then after effect is reverse. So optimum result can be found for $3^{\text {rd }}$ level of Gap Voltage will be preferable. Hence Optimum set of process parameter can be concluded as Peak level-1, Pulse level-2, Gap level-3 i.e. best suitable set of process parameter for optimum result will be (according to Principle Component Analysis)

Peak Current- 10 ampere, Pulse On Time- 100 Micro Second, Gap Voltage- 50 Volt.

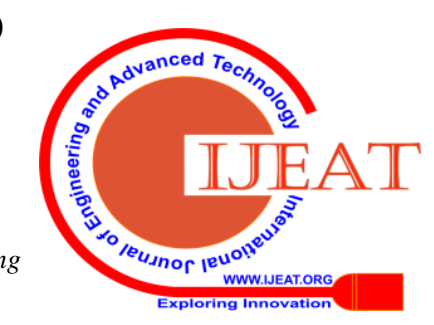


Optimization of Process Parameters of EDM of Inconel 617 by Taguchi based PCA and GRA technique and effect of recast layer formation

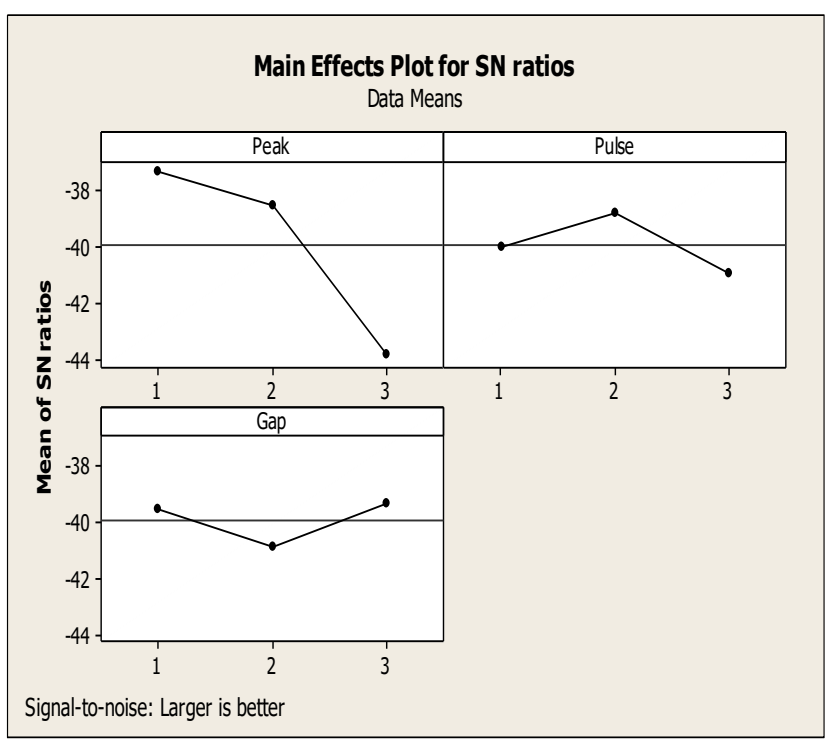

Fig.5. Main effect plot for SN ratios on MPI

Result of ANOVA analysis

Source DF Seq SS Adj SS Adj MS F P

$\begin{array}{llllllll}\text { Peak } & 2 & 71.007 & 71.007 & 35.504 & 13.15 & 0.071\end{array}$

$\begin{array}{lllllll}\text { Pulse } & 2 & 7.138 & 7.138 & 3.569 & 1.32 & 0.431\end{array}$

$\begin{array}{lllllll}\text { Gap } \quad 2 & 2.167 & 4.167 & 2.084 & 0.77 & 0.565\end{array}$

Residual Error $2 \quad 5.402 \quad 5.402 \quad 2.701$

Total $\quad 887.714$

Also ANOVA analysis of result of MPI shows that For optimum result i.e. set of Higher MRR as well as lower TWR, Peak Current is most significant. Secondly Pulse on time.

Gap Voltage has least effect on MRR and TWR.

B. Grey Relation Analysis

Table- 9: Grey Relation Generation

\begin{tabular}{|c|c|c|c|c|}
\hline & \multicolumn{2}{|c|}{ Normalized response } & \multicolumn{2}{|c|}{$\Delta=1-\mathrm{x}_{\mathrm{i}}(\mathrm{k})$} \\
\hline & MRR & TWR & MRR & TWR \\
\hline 1. & 0.798443 & 0.830437 & 0.201557 & 0.169562 \\
\hline 2. & 0.783254 & 0.988341 & 0.216746 & 0.011659 \\
\hline 3. & 0.542066 & 1 & 0.457934 & 0 \\
\hline 4. & 1 & 0.613671 & 0 & 0.386326 \\
\hline 5. & 0.845844 & 0.846059 & 0.154156 & 0.153937 \\
\hline 6. & 0.688946 & 0.828815 & 0.311054 & 0.171181 \\
\hline 7. & 0.902970 & 0 & 0.09703 & 1 \\
\hline 8. & 0.530481 & 0.553286 & 0.469519 & 0.446711 \\
\hline 9. & 0 & 0.743648 & 1 & 0.256348 \\
\hline
\end{tabular}

Table- 10: Grey Relation Grade

\begin{tabular}{|c|c|c|c|c|}
\hline & \multicolumn{2}{|c|}{$\begin{array}{l}\text { Gray Relation } \\
\text { coefficient } \\
\left(\Delta^{\min }+€ \Delta^{\max )} /\right. \\
\left(\Delta_{\mathrm{i}}+€ \Delta^{\max }\right)\end{array}$} & \multirow[t]{2}{*}{\begin{tabular}{|l} 
Gray relation \\
grade \\
$=$ average of \\
grey \\
relation \\
coefficient \\
GRG(OQPI)
\end{tabular}} & \multirow[b]{2}{*}{ Rank } \\
\hline & MRR & TWR & & \\
\hline 1. & 0.712700 & 0.746757 & 0.729729 & 5th \\
\hline 2. & 0.697597 & 0.977213 & 0.837405 & 1st \\
\hline 3 & 0.521957 & 1 & 0.760979 & 4th \\
\hline
\end{tabular}

\begin{tabular}{|l|l|l|l|l|}
\hline 4 & 1 & 0.564127 & 0.782064 & 2nd \\
\hline 5 & 0.764344 & 0.764600 & 0.764472 & 3rd \\
\hline 6 & 0.616482 & 0.744956 & 0.680719 & 6th \\
\hline 7 & 0.837479 & 0.333333 & 0.585406 & 7th \\
\hline 8 & 0.515720 & 0.528144 & 0.521932 & 8th \\
\hline 9 & 0.333333 & 0.661071 & 0.497202 & 9th \\
\hline
\end{tabular}

Experimental Values clearly shows that set of Peak1, Pulse2, Gap2 has Maximum Value of GRG, Hence in L9 orthogonal array this set, is optimum. However the optimum level of Process Parameter can be further analysed by drawing main effect plot using Taguchi Design in Minitab software.

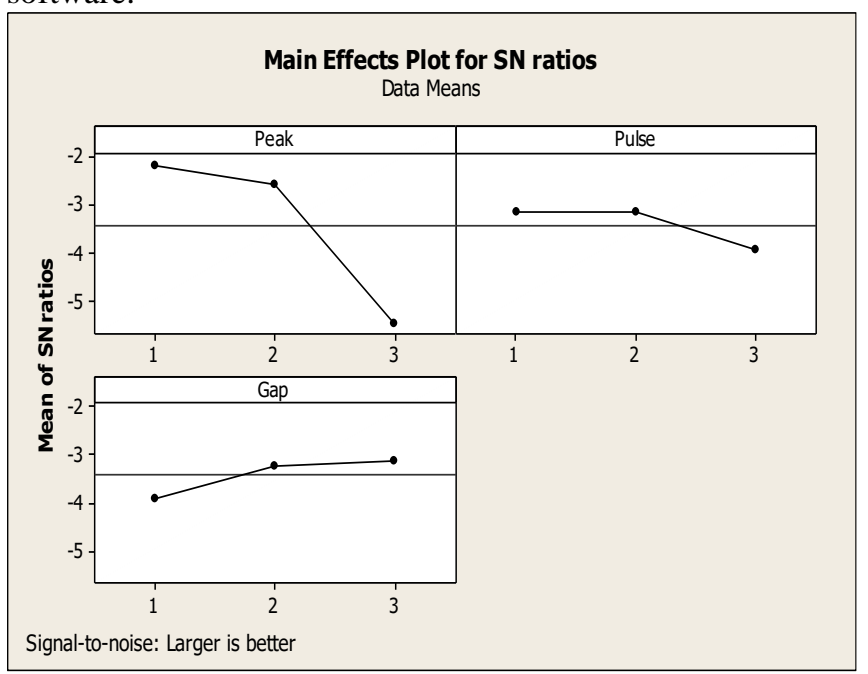

Fig. 6. Main Effect plot for SN ratios on GRG

By Analyzing Main Effect Plot for S/N ratio of Grey Relation Grade, it can be seen that with increase in Peak Current optimum response variables are degrading i.e. GRG is decreasing.

After some point of time increase in pulse on time will decrease the value of GRG and hence deviation will occur from optimum response.

With increase in Gap Voltage there will be deviation from optimum result because GRG will decrease.

Hence, best suitable parameters for optimum response will be Peak1, Pulse2 and Gap3

i.e. Peak Current 10 ampere, Pulse on Time 100 micro second and Gap Voltage 75 Volt.

Analysis of Variance for SN ratios of GRG

Source DF Seq SS Adj SS Adj MS F $P$

$\begin{array}{lllllll}\text { Peak } & 2 & 18.7811 & 18.7811 & 9.3905 & 42.96 & 0.023\end{array}$

$\begin{array}{lllllll}\text { Pulse } & 2 & 1.1353 & 1.1353 & 0.5676 & 2.60 & 0.278\end{array}$

$\begin{array}{llllllll}\text { Gap } & 2 & 1.0757 & 1.0757 & 0.5379 & 2.46 & 0.289\end{array}$

Residual Error 20.43720 .43720 .2186

Total 821.4292

Rank- Peak1 Pulse3 Gap2

By Analysis of Variance it can be clearly seen that Peak Current is most significant parameter on EDM of Inconel 617. Secondly Pulse on Time and then Gap Voltage. Hence gap voltage has least effect on Response Parameters. 


\section{Comparing the results of Grey Relation Analysis and Principle Component Analysis}

Both the Analysis on experimental data shows the same result that the $2^{\text {nd }}$ reading is optimum, that is Peak Current 10 ampere,

Pulse on Time 100 micro second and Gap Voltage 50 Volt, where as their main effect plot shows the almost same pattern for peak current and pulse on time, but the pattern of gap voltage is slightly different. Both Analysis shows the same set of process parameter for optimum result by Main Effect Plot also.

\section{Individual effect on MRR}

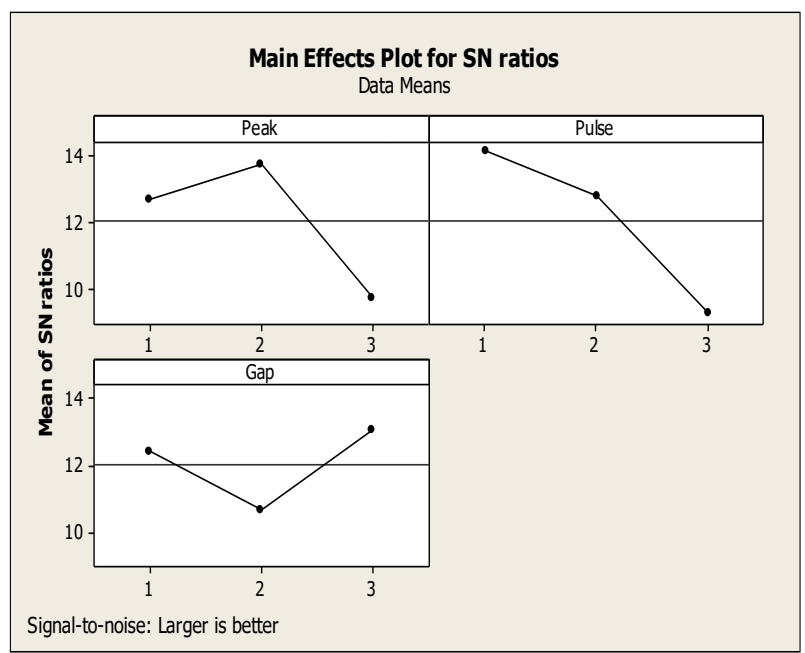

Fig.7. Main Effect Plot for SN ratios on MRR

It can be seen clearly that at some extent with increase in Peak current, MRR will increase but after that, increase in Peak Current will cause reduction in MRR. Increase in Pulse On Time will cause reduction in MRR. Gap voltage has varying effect on MRR. At first increase in Gap Voltage will cause reduction in MRR but after that increase in Gap Voltage will cause reduction in MRR.

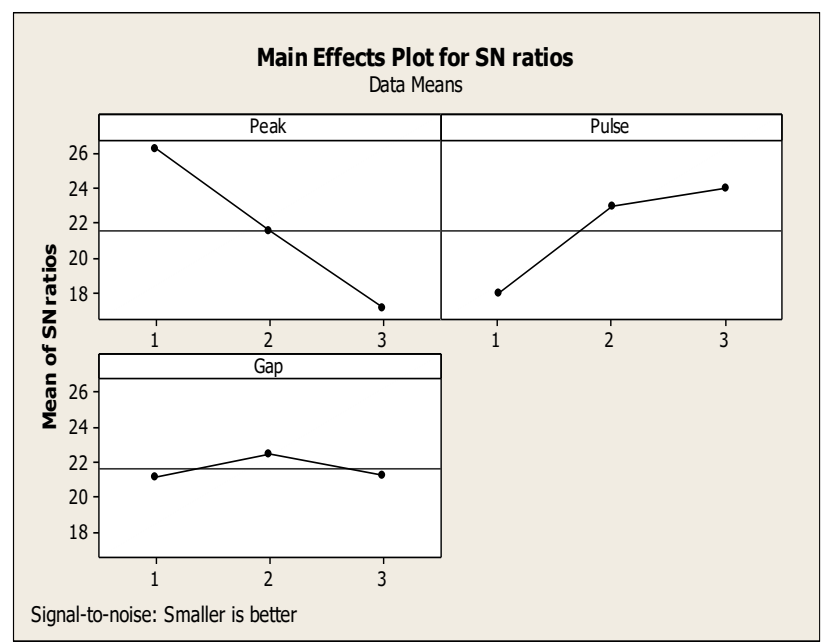

Fig.8. Main Effect plot for SN ratios on TWR

Main effect plot of TWR shows that TWR is decreasing with increase in Peak Curreent but Increasing with increase in Pulse on Time. Gap Voltage has varying effect on TWR. At first increase in Gap Voltage will cause increse in MRR but after that extent increase in Gap Voltage will cause Increase in TWR. Optimum set of Process Parameter for least MRR is Peak3, Pulse1, Gap1 i.e. Peak Current- 20 ampere, Pulse on Time- 50 micro second, Gap Voltage- 25 Volt.

\section{E. Analyzing the effect of recast layer}

After reviewing many research journal one can conclude that at lower range of Peak Current and Pulse on time for lower depth of cut, MRR increases with increase in Peak Current and Pulse on Time. But at higher depth of cut, at high Peak Current and pulse on time this pattern can change. And this change is analyzed in this project.

At high Peak Current and pulse on time amount of molten metal formed during sparking is although large yet MRR is small because of the constant flushing pressure. To remove large amount of molten metal from work surface there is need of high flushing pressure, but in this project fluid pressure is kept constant at 0.6 bar hence at high depth of cut and at high peak current and Pulse on time, the flushing pressure is not sufficient to remove the high amount of molten metal, so this molten metal again re-solidify and form recast layer during pulse off time, without being flushed out. Hence this reduces the MRR.

When pulse on time is large, spark is generated for long time, causing more material to melt but again this molten material can't be removed by keeping fluid pressure constant. To remove this extra material flushing pressure should be increased.

Recast layer has least effect on Gap Voltage. The effect of Gap voltage is almost same as previous. That is by increasing Gap Voltage MRR decreases for some extent after that MRR increases with increase in gap voltage.

As mentioned earlier that with increase in Peak current TWR increase, But because of the formation of recast layer, some part of molten metal can also solidifies on the tool and hence Tool wear rate can decrease with increase in peak current during recast layer formation and the same thing has been observed in this experiment. Main effect plot of TWR clearly shows that TWR increases with.

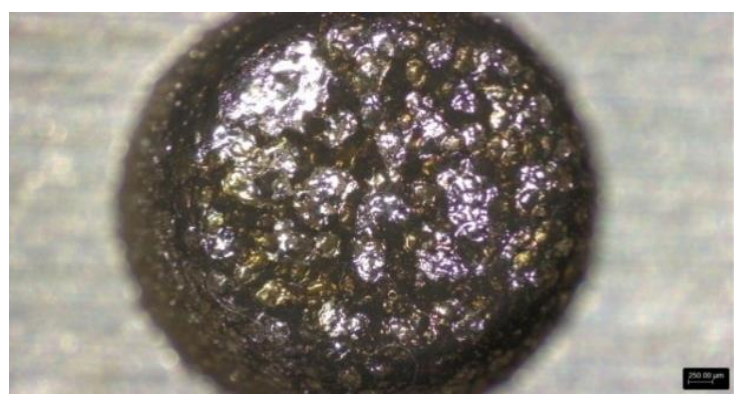

Fig 9.1.first reading

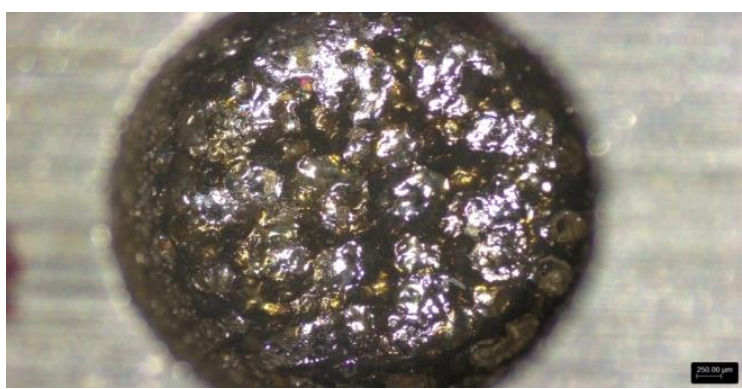

Fig. 9.2.second reading 

and effect of recast layer formation

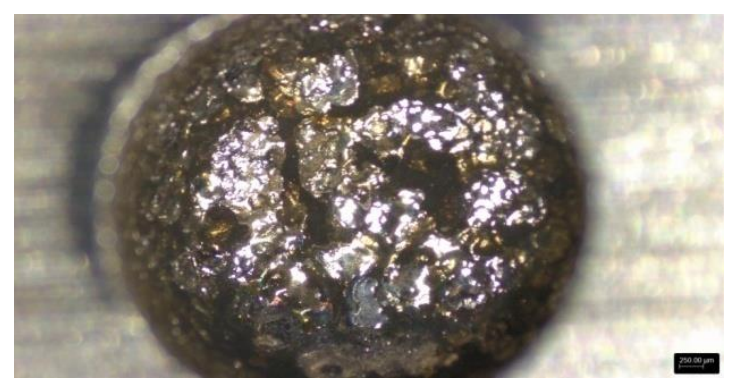

Fig. 9.3.third reading

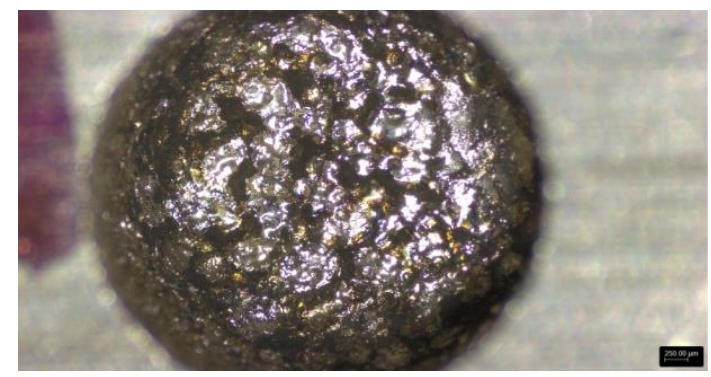

Fig. 9.4.fourth reading
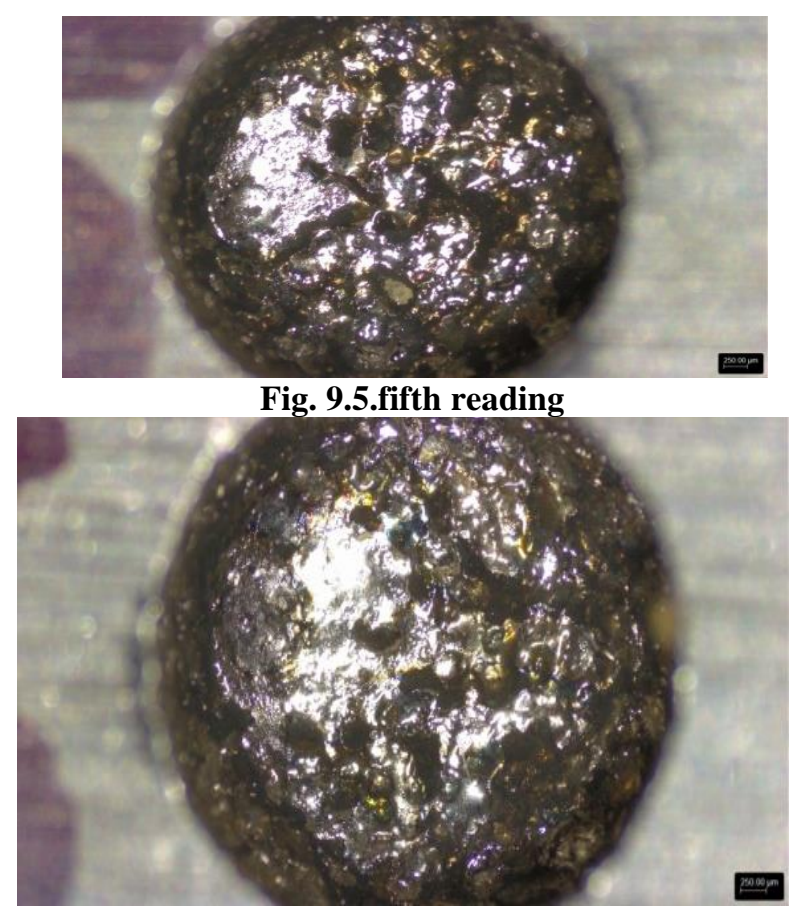

Fig.9.6 sixth reading

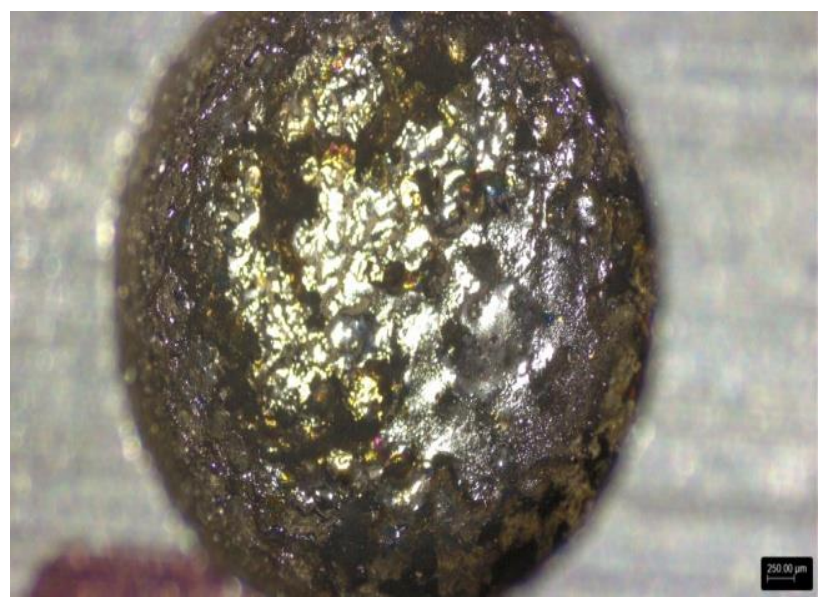

Fig.9.7 seventh reading

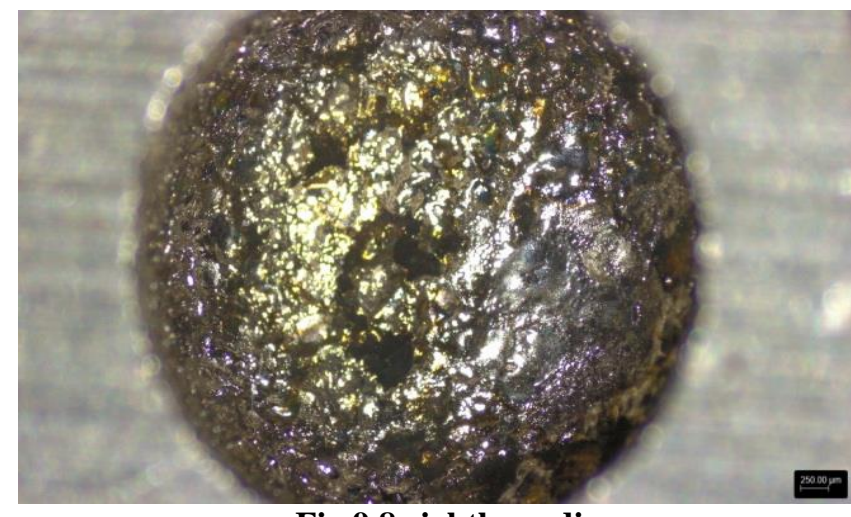

Fig.9.8 eighth reading

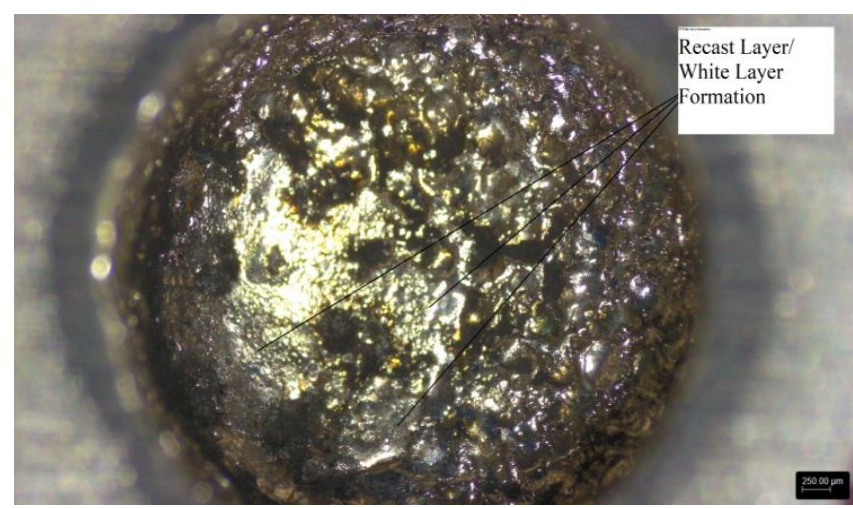

Fig. 9.9 ninth reading

It can be seen that in Fig.9.7, 9.8, 9.9 at high current recast layer/ White layer formation occurred in large extent. In these figures less no. of surface pores/holes are there, which is due to recasting of molten metal on the surface. It denotes that at High Current and Pulse on Time recast layer formation occurs in large extent.

\section{VI.CONCLUSION}

For Inconel 617 EDM has been performed by considering three process parameter Peak Current, Pulse on Time, Gap Voltage taking their 3 levels and keeping other process parameter as constant and performing EDM up to $3 \mathrm{~mm}$ depth. Conclusion can be drawn For EDM of Inconel 617

- According to main effect plot optimum set of process parameters are Peak1, Pulse2, Gap3. That is Peak Current 10 ampere, Pulse on Time 100 micro second, Gap Voltage 75 volt for making hole up to $3 \mathrm{~mm}$ depth

- $\quad$ Peak current is most significant factor affecting MRR and TWR.

- Gap Voltage is least significant factor affecting MRR and TWR

- Combined effect of process parameter On MRR and TWR can be understood by the main effect plot of S/N ratio of MPI and GRG. Both indicate that MRR is decreasing with increase in Peak Current.

- According to MPI that is Principle Component Analysis MRR first increases with increase in Pulse On Time but after 100 micro second, MRR decreases with increase in Pulse on Time. Grey Relation Grade Main effect plot also shows decrease in MRR after 100 micro second.

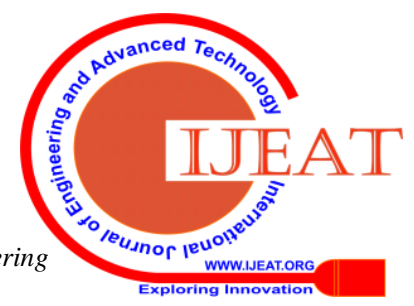


- According to MPI that is Principle Component Analysis MRR first decreases with increase in Gap Voltage Gap Voltage. According to GRG that is Grey Relation, MRR is continuously increases with increase in Gap Voltage. Hence Pulse on Time and gap Voltage effect pattern is slightly different in both analysis techniques.

- The effect of process parameter individual on MRR that is $\mathrm{S} / \mathrm{N}$ ratio of MRR individually shows that MRR first increase with increase in Peak Current but after 15 ampere MRR starts to decrease with increase in Peak Current. With increase in Pulse on Time MRR is continuously decreasing. MRR decreases with increase in Gap Voltage up to 50 Volt then after MRR increases.

- The effect of process parameter individual on TWR that is $\mathrm{S} / \mathrm{N}$ ratio of TWR individually shows that TWR decreases with increase in Peak Current because of formation of Recast Layer. With increase in Pulse on time TWR is increasing.

With increase in Gap Voltage TWR is $1^{\text {st }}$ increasing

then after 50 Volt it is decreasing.

- $\quad$ Stereo Optical Microscope Image of machined work material shows that for $7^{\text {th }} 8^{\text {th }}$ and $9^{\text {th }}$ experiment recast layer formation is continuously increasing which may be because of Increase in Pulse on Time and Peak Current, so recast layer adversely affect MRR and TWR.

Although for lower depth of cut and low range of peak current MRR rate increases with increase in peak current but for higher depth and high peak current MRR decrease with increase in Peak Current because of the formation of Recast layer and insufficient fluid pressure.

\section{Appendix}
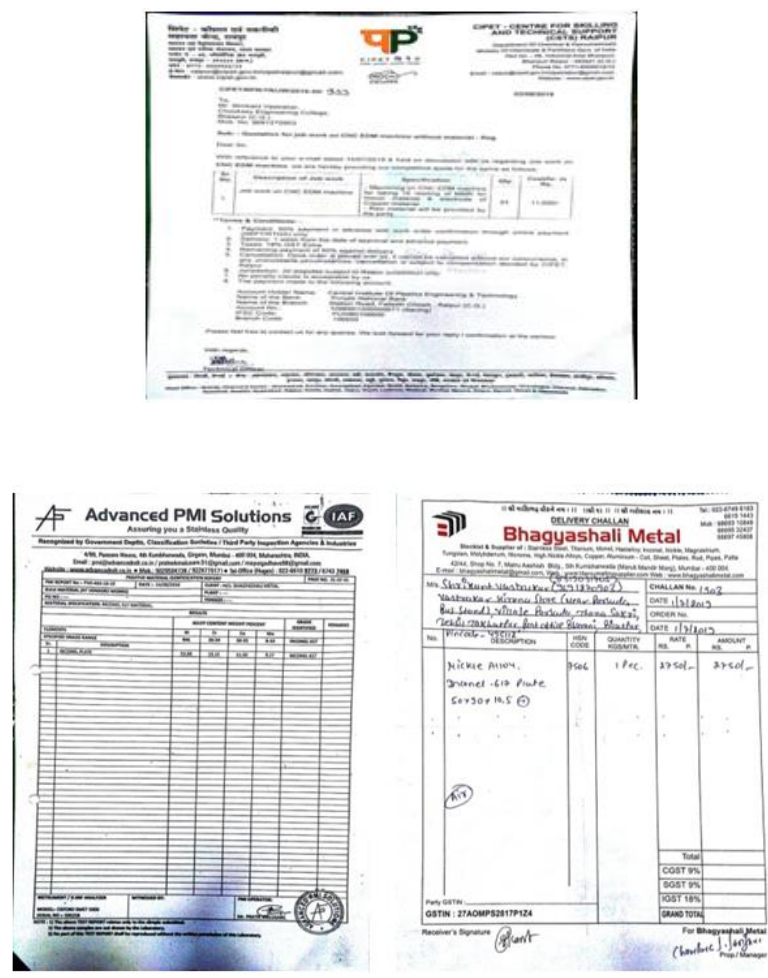

\section{REFERENCES}

1. Bruzzone, A. A., \& Lonardo, P. M. (1999). Effect of Flushing and Electrode Material on Die Sinking EDM. Genoa, Italy: Department of production engineering university of Genoa.

2. Chandramouli, S., Balraj, S., \& Eswaraiah, K. (2014). Optimization of Electrical Discharge Machining Process Parameters Using Taguchi Method. International Journal of Advanced Mechanical Engineering , 4, 425-434.

3. Das, M. K., Kumar, K., \& Barman, T. k. (2014). Optimization of MRR and Surface Roughness in PAC of EN 31 Steel Using Weighted Principal Component Analysis. Procedia Technology Elsevier , 14, 211-218.

4. Doss, R. S., \& Kumaraguruparan, B. (2015). Optimization of Process parameter in EDM on Inconel by using robust design. Journal of Chemical and Pharmaceutical Sciences (6), 316-319.

5. Ghewade, \& Nipanikar, S. R. (2011). Electro Discharge Machining of Inconel Material. International Journal of Engineering Research and Technology , 4, 157-169.

6. Guo, X. X. (2008). Optimization Method of Grey Relation Analysis Based on the Minimum Sensitivity of Attribute Weights. Wuhan University of Technology, 177-189.

7. Harshalkumar, Mundane, R., Kale, A. V., \& Giri, J. P. (2018) Findings of performance evaluation of EDM for different materials of electrodes and work pieces. International Journal of Engineering \& Technology , 7(4.5), 542-547.

8. Jabbaripour, B., Sadeghi, M. H., Faridvand, S., \& Shabgard, M R. (2012). Investigating the effect of EDM parameters on surface intigrity, MRR and TWR in machine of Ti-6Al-4V. Machining Science and Technology,Tyler and Francis , 16, 419444.

9. Kansal, H. K., Singh, S., \& Kumar, P. (2005). Application of Taguchi method for optimisation of powder mixed electrical discharge machining. Int. J. Manufacturing Technology and Management , 7, 329-341.

10. Katamreddy, S. C., Punnath, N., \& Radhika, N. (2018). Multiresponse optimisation of machining parameters in electrical discharge machining of Al LM25/AlB2 functionally graded composite using grey relation analysis. Int. J. Machining and Machinability of Materials , 20 (3), 193-213.

11. Kewther, A., Yilbas, B. S., \& Hashmi, M. S. (2001). Corrosion Properties of Inconel 617 Alloy after Heat Treatment at Elevated Temperature. JMEPEG , 108-113.

12. Khadarbasha, S. K., Kolli, M., \& Jagannadha, M. V. (2018). Parametric optimization of Edm on Hastelloy C-276 Using Taguchi L18 Technique. International Journal of Engineering \& Technology, 7 (2.7), 714-716.

13. Koyanoa, T., \& Suzukia, S. (2016). Study on the Effect of External Hydrostatic Pressure on Electrical Discharge Machining. Elsevier , 42, 46-50.

14. Kuoa, Y., Yangb, T., \& Huangb, G. W. (2008). The use of a grey-based Taguchi method for optimizing multi-response simulation problems. Engineering Optimization Tyler and francis group , 40 (6), 517-528.

15. L. Li, Z. Y. (2015). Machining Characteristics of Inconel 718 by Sinking-EDM and Wire-EDM. Materials and Manufacturing Processes Tylor and Francis , 30, 968-973.

16. Makenzi, M. M., \& Ikua. (2012). A review of flushing techniques used in electrical discharge machining. Proceedings of the 2012 Mechanical Engineering Conference on Sustainable Research and Innovation , 162-165.

17. Mishra, D. K., Datta, S., Masanta, M., \& Mahapatra, S. S (2018). Through hole making by electro-discharge Machining on Inconel 625 super alloy using hollow copper tool electrode. Journal of Process Mechanical Engineering , 0(0), 1-23.

18. Mohanta, M. K., \& Maity, K. P. (2013). Optimization of micro wire electro discharge machining process parameter using aerospace material. National Institute of Technology, Rourkela , $1-74$.

19. Muthuramalingam, T., \& Mohan, B. (2013). Multi-Response Optimization of Electrical Process Parameters on Machining Characteristics in Electrical Discharge Machining Using Taguchi-Data Envelopment Analysis-Based Ranking Methodology. Journal Of engineering and technology Anna University , 3 (1), 57-59.

20. Ning Li, Y. J. (2018). Multi-response optimization of Ti-6Al-4V turning operations. Advance Manufacturing University of Science and Technology, Wuhan , 7, 142-154.

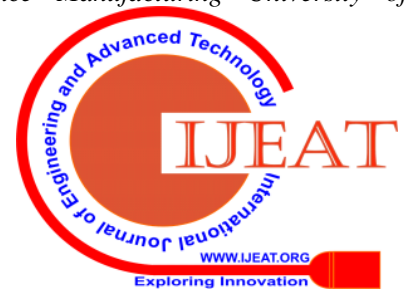




\section{Optimization of Process Parameters of EDM of Inconel 617 by Taguchi based PCA and GRA technique and effect of recast layer formation}

21. Nipanikar, S. R. (2012). Parameteric optimization of electro discharge machining of AISI D3 steel material using Taguch method. Journal of Engineering Research and Studies , 3 (3), 7 10.

22. Niranjan D, G. S. (2017). Optimization of Cutting Process Parameters on AL6061 Using ANOVA and TAGUCHI Method. Elsevier Material today , 4, 10845-10849.

23. Ojha, K., Garg, R. K., \& Singh, K. K. (2010). MRR Improvement in Sinking Electrical Discharge Machining. Journal of Minerals \& Materials Characterization \& Engineering , 9 (8), 709-739.

24. Ostertagova, E., \& Ostertag, O. (2013). Methodology and Application of One-way ANOVA. American Journal of Mechanical Engineering , 1 (7), 256-261.

25. Patel, N. K., \& Maity, K. P. (2014). Parametric Optimization of Process Parameters For EDM of Stainless Steel 304. A Thesis Rourkela, Odisha, India: NIT Rourkela.

26. Rahul, Kumar, A., Datta, S., Biswal, B. B., \& Mahapatra, S. S. (2017). Machining performance optimisation during EDM of Inconel 718: a case experimental investigation. Int. J. Productivity and Quality Management , 21 (4), 460-488.

27. Rajamanickam, S., Manjunathan, R., Palani, R., Mohamed, J. P. Monesh, D., \& Akash, A. (2018). Experimental Analysis of Electric Discharge Machining Over Inconel 825 Using Copper Electrode and Al2O3 Coated Copper Electrode. International Journal of Engineering \& Technology , 7 (2.33), 1302-1304.

28. Rajesha, S., Sharma, A. K., \& Kumar, P. (2005). Some Aspects of Surface Integrity Study of Electro Discharge Machined Inconel 718. Mechanical and Industrial Engineering Department, Indian Institute of Technology Roorkee , 440-444.

29. Sahu, P., \& Maity, K. P. (2015). Experimental Investigation and Optimization of Parameters in Electrochemical Machining Operation. Rourkela, Odisha, India: NIT Rourkela.

30. Sin Yong Teng, B. S. (2019). Principal component analysisaided statistical process optimisation (PASPO) for process improvement in industrial refineries. Brno University of Technology Czech republic: Journal Of cleaner Production.

31. Somnath, Kale, M., \& Khedekar, D. S. (2016). Optimization of Process parameters in EDM for Machining of Inconel 718 using Response Surface Methodology. International Journal of Innovations in Engineering and Technology (IJIET) , 7 (3), 188193.

32. Son, S. M., Limb, H. S., Kumarb, A. S., \& Rahmanb, M. (2007). Influences of pulsed power condition on the machining properties in micro EDM. Journal of material processing technology Elsevier , 190, 73-76.

33. Sonwane, \& Kulkarni, M. L. (2018). Multi Response Optimization of Wire Electrical Discharge Machining for Titanium Grade-5 by Weighted Principal Component Analysis. International Journal of Engineering and Technology Innovation , 8 (2), 133-145.

34. Upadhyay, C., Rahul, Datta, S., Mahapatra, S. S., \& Biswal, B. B. (2018). An experimental investigation on electro discharge. Int. J. Industrial and Systems Engineering , 29 (2), 233-249.

- $\quad$ and after 50 volt, MRR increases with increase in

Websites

www.specialmetals.com

www.inderscienceonline.com

www.sciencedirect.com

www.springer.com

\section{AUTHORS PROFILE}

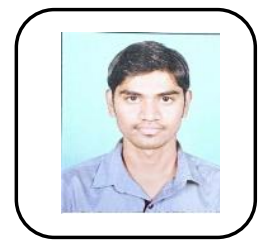

ShrikantVastrakar, pursuing M.techScholar, Mechanical Engineering Department, Chouksey Engineering College Bilaspur. He has presented Research papers in more than 01 International Conferences and attended 01workshops. He has keen interest in investigating on non-conventional machining..

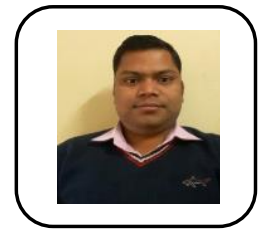

Sharda Pratap Shrivas, Assistant Professor, Mechanical Engineering Department, Chouksey Engineering College Bilaspur under Chhattisgarh Swami Vivekananda University Bhilai. He has published more than 10 Research papers in International journal and Conference proceedings. He has presented Research papers in more than 10 National and International Conferences and attended/organise various workshops. $\mathrm{He}$ has keen interest in investigating the Conventional and nonconventional machining process.

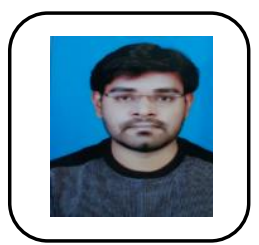

Amit Kumar Vishwakarma, Assistan Professor, Mechanical Engineering Department, Chouksey Engineering College Bilaspur under Chhattisgarh Swami Vivekananda University Bhilai. He has published 8 research paper in various international and national journals. He has keen interest in production and manufacturing

process.

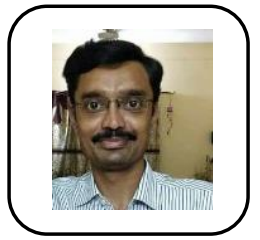

Sanjay Kumar Vaidya, Assistant Professor, Mechanical Engineering Department, Chouksey Engineering College Bilaspur under Chhattisgarh Swami Vivekananda University Bhilai. He has published more than 7 research paper papers in various national and international journals and 5 papers in conference proceeding. He has keen interest in welding and production engineering.

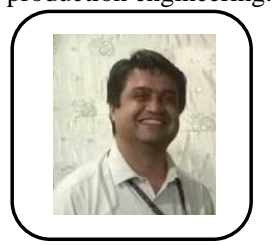

Ashish Kumar Khandelwal, Head of Department of Mechanical Engineering, Chouksey Engineering College Bilaspur under Chhattisgarh Swami Vivekananda University Bhilai. He has published more than 16 research papers in various international and national manufacturing processes. 